\title{
Mortality-risk valuation, age and cause of death: out-of- hospital cardiac arrest
}

\author{
BJÖRN SUND 1,2,3* \\ ${ }^{1}$ Department of Economics, Karlstad University, Karlstad, Sweden \\ ${ }^{2}$ Swedish Business School, Örebro University, Örebro, Sweden \\ ${ }^{3}$ Swedish Civil Contingencies Agency (MSB), Karlstad, Sweden
}

\begin{abstract}
Economic evaluation of policies regarding out-of-hospital cardiac arrest (OHCA) is important. The value of a statistical life (VSL) for OHCA victims is the most important component in a cost-benefit analysis of interventions that have the possibility to reduce mortality from this cause. This value is not known. We use responses to a national Swedish mail survey, based on the stated-preference technique to directly elicit individuals' hypothetical willingness to pay for a reduced risk of dying from OHCA. A lower-bound estimate of VSL for OHCA would be in range of SEK 30 to 50 million. The value is found to be higher than for comparable VSL estimates from the transport sector, even though individuals who suffer OHCAs are generally older and less healthy than people who die in road traffic accidents. The results indicate that it is not an overestimation to use the 'baseline' VSL value from the transport sector (SEK 24 million) in cost-benefit analysis of OHCA policy decisions and that the cause of death is important when examining willingness to pay for death risk reductions. We do not support a general declining VSL due to the age of the victims, i.e. a 'senior death discount', for this cause of death.
\end{abstract}

JEL classification: D61, I14, I18

Key words: cost-benefit analysis, value of life, senior death discount, cardiac arrest

\section{Introduction}

Establishing a monetary value of a human statistical life (VSL) is a sensitive issue in several aspects. Religious, moral and ethical beliefs are challenged and the allocations of scarce economic resources are not always consistent with these beliefs. The human capital approach equates the value of a human life to the discounted market value of the output produced by an individual over an expected lifetime, but the value does not account for output outside the workplace. The old, the poor, the disabled, the sick or those with any other personal attribute that may decrease their 'productivity' would have reduced VSL values. This could lead to that we would ignore expenses that reduce the risk of dying for individuals whose value do not cover their cost of living. Instead, VSL can be determined

*Correspondence to: Björn Sund, Swedish Civil Contingencies Agency (MSB), SE-651 81 Karlstad, Sweden. E-mail: bjorn.sund@msb.se

Published: Online January 2017. In print December 2017. dx.doi.org/10.5617/njhe.2374 
by the willingness to pay approach, but does this approach also produce different VSL values based on the attributes of the victims?

Heterogeneous value of life is an extremely sensitive issue and in the US there have been legislation proposals against reduction of VSL values based on individual heterogeneity (Viscusi, 2010). Empirically it has been shown that heterogeneity of VSL regarding various ages is substantial, and international practices have often been to decrease VSL with age, i.e. a 'senior death discount' (Viscusi, 2010; Aldy and Viscusi, 2007; Krupnick, 2007). ${ }^{1}$ On the other hand, this policy has also been argued not to be supported by theoretical or empirical findings (Krupnick, 2007; Evans and Smith, 2006). Generally, it is unclear how the age-dimension should be treated in cost-benefit analysis (Hultkrantz and Svensson, 2012).

Estimates of VSL in Sweden vary from 10 to 100 million Swedish kronor (SEK) and are typically based on valuations from the transport sector (Hultkrantz and Svensson, 2012; Svensson, 2009; Persson et al., 2001; Hultkrantz et al., 2006). The Swedish Transport Administration recommends a VSL of SEK 24 million and VSL values for road traffic casualties are roughly the same in similar European countries (Trafikverket, 2012; HEATCO, 2006). Other causes of death than vehicular accidents are scarcely examined in the literature and it is possible that a lower VSL for the elderly applies to only certain causes of death (Krupnick, 2007).

The aim of this study is to estimate VSL for out-of-hospital cardiac arrest (OHCA) based on the stated-preference technique contingent valuation (CV). Our hypothesis was that the VSL for OHCA would be lower than SEK 24 million, since individuals who suffer OHCAs are generally older and less healthy than people who die in road traffic accidents. An avoided traffic-accident fatality on average saves 35-40 years of remaining life time, while an avoided OHCA fatality saves only 6 years (Hultkrantz and Svensson, 2012; Sund et al., 2012).

Our results show that a conservative VSL for OHCA would be in the range of SEK 30 to 50 million, which is higher than the official VSL for road traffic safety in Sweden. The results indicate that there is no reason to suspect that the official VSL value constitutes an overestimation when used in connection with OHCA interventions. Also, our results do not support the practice of decreasing VSL with age ('senior death discount') for victims of cardiac arrest.

\section{Methods}

\subsection{The value of a statistical life}

The value of a statistical life (VSL) is a measure of the trade-off between income and mortality risk reductions. In essence, this means that VSL is the value that society deems economically efficient to spend on avoiding one (unidentified) premature death, i.e. if the mean VSL is higher than the cost per head, then the project should proceed since the losers can be compensated by the gainers (Hicks-Kaldor criteria). Especially in environmental, health and transport safety economics, VSL is often a key input in policy evaluations when performing cost-benefit analysis (CBA). In a standard theoretical model of one individual's baseline mortality risk $(p)[0 \leq p \leq 1]$, where $u_{a}(\mathrm{y})$ and $u_{d}(\mathrm{y})$ are the individual's utility as a

\footnotetext{
${ }^{1}$ We define 'senior death discount' as the expected lower VSL for cardiac arrest victims compared to road traffic victims, where the expected mean age of the victims are lower. The discount does not have reference to the variation of the age of the respondents within the study sample.
} 
function of income $(y)$ conditional on staying alive $(a)$ and dying $(d)$, the expected utility is equal to (Jones-Lee, 1974; Alberini, 2005):

$$
E U[p, y]=(1-p) u_{a}(y)+p u_{d}(y) .
$$

The model is simplified to only consider a marginal change in the probability of one individual's own death and also within a specified time period. Assuming that utility of income is zero when the individual is dead $\left(u_{d}=0\right)$ simplifies the expression to $(1-p) u_{a}(y)$. Then the trade-off between income and risk is (Carson and Groves, 2007; Arrow et al., 1993):

$$
V S L=\frac{d y}{d p}=\frac{u_{a}(y)}{(1-p) u_{a}^{\prime}(y)}
$$

In other words, the VSL is the marginal rate of substitution (MRS) between income and survival probability, that is, (the negative of) the slope of the indifference curve at a specific point $(y, p)$. WTP represents the maximal amount that an individual is willing to pay for a specified risk reduction $(\Delta \mathrm{p})$. Then, VSL is estimated as:

$$
V S L=\frac{W T P}{\Delta p}
$$

Through our survey we measure WTP for a hypothetical risk reduction of dying from OHCA and arrive at a VSL measure that is specific for this diagnosis and the scenario in the survey.

\subsection{Contingent valuation survey and data}

Contingent valuation $(\mathrm{CV})$ is a survey-based stated preference technique that is used to directly elicit individuals' hypothetical willingness to pay (WTP) for certain non-market goods or services (Bateman et al., 2002). The method has been applied to health care since the 70s and although exposed to criticism, it has the potential to deliver measures of costs and consequences in monetary terms (Klose, 1999; Kling et al., 2012).

The target population for our CV survey consisted of the inhabitants of Sweden and we randomly sampled 1000 individuals aged 17-75. 400 more individuals were sampled for a test of scope bias, but the detailed result of this analysis is reported elsewhere (Sund, 2009). The survey mode was a mail survey that was sent out in June 2007 followed by a reminder mailed out three months later in September. Our overall response rate was 43 percent. Table A2 in the Appendix summarises the sample statistics.

A logit regression on WTP, including the observed demographic variables, was performed to check if there was a significant relation (Table 1). The results show a significant negative parameter estimate for the bid level, but none of the other variables turned out to have a significant relation to WTP. We also included dummy variables for 'senior age' $(>40$ years, $>45$ years, $\ldots)$ and found that the parameter estimate were significant for ages $>45(\mathrm{P}=0.086),>50(\mathrm{P}=0.087),>55(\mathrm{P}=0.018)$ and $>60(\mathrm{P}=0.002)$ years,

\footnotetext{
${ }^{2}$ The respondents were randomly sampled by SPAR (Statens personadressregister), which includes all persons who are registered as resident in Sweden.
} 
but not for $>65$ and $>70$ years. The conclusion from this "inverted-U" shape is that it follows the pattern of other studies from different contexts and that we capture other factors than a pure age effect (e.g. a correlation with income). If the increasing risk of suffering from an OHCA due to age would reflect WTP, we would expect the effect to last for the respondents older than 65 years.

Table 1: Estimated WTP (probability of a yes-answer), marginal effects (logit model)

\begin{tabular}{|c|c|}
\hline Variable & Full sample \\
\hline Gender & $0.017(0.770)$ \\
\hline Age (10 years) & $0.023(0.237)$ \\
\hline High education & $-0.014(0826)$ \\
\hline Low education & $0.029(0.739)$ \\
\hline High risk & $-0.044(0.624)$ \\
\hline Low risk & $-0.073(0.274)$ \\
\hline Income $(\text { SEK } 10000)^{3}$ & $-0.013(0.422)$ \\
\hline Population (in 100 000) & $-0.011(0.406)$ \\
\hline Heart & $0.09(0.327)$ \\
\hline Bid (SEK 100) & $-0.19 *(0.000)$ \\
\hline Log-likelihood & -190.05 \\
\hline Number of respondents & 334 \\
\hline
\end{tabular}

We performed a pilot study with a sample of 100 individuals in May 2007 to pretest the questionnaire and to establish an interval for the majority of the WTP values. An open-ended (OE) elicitation format was used in the pilot survey, while we used a discretecontinuous $\mathrm{CV}$ format in the main study where both dichotomous choice (DC) and OE questions were asked to the same sample of respondents. The dichotomous choice (closedended) question in our survey was: 'How would you vote if your personal fee was SEK X

\footnotetext{
${ }^{3} \mathrm{We}$ are aware that it is theoretically problematic to include income as an independent variable in the WTP regression for DC questions, since utility is assumed to be linear in income (Hanemann, 1984). However, we do not interpret income as 'income per se' but instead as a proxy for household characteristics and focus on the empirical relationship.

${ }^{4}$ An inconsistent respondent answered yes (no) to the DC bid and then gave an OE answer that was lower (higher) than the bid.
} 
per year (i.e total SEK $10 \times X$ for 10 years), for this programme to be implemented in your municipality? Answer: I would vote: $\square$ Yes $\square$ No', while the open-ended question was: 'Provided that the programme is carried out, how much would you at most be willing to pay annually for the implementation of the programme, that reduces your own risk as well as the risk of all other individuals in your municipality for a cardiac arrest mortality? Answer: ......SEK per year' ${ }^{5}$ Also, a follow-up certainty scale of 1 (very uncertain) to 10 (very certain) was used after both WTP questions.

When calculating VSL, the DC data is deemed more valid since valuing new public goods with coercive payment implies incentive compatibility and also since a binary question better resembles a real market situation. Incentive compatibility implies that 'a truthful response to the actual question asked constitutes an optimal strategy for the agent' (Carson and Groves, 2007). Since DC data has more desirable theoretical properties and it is the standard approach in estimating VSL, we will use it in the following analysis.

The valuation scenario was a public programme to increase the survival rate after OHCA by increasing the density of defibrillators in the municipality. Defibrillation was explained to be initiated by firemen, policemen, security guards or nurses, and public access defibrillators may be located in hotels, shopping malls, sports centres and theatres. The willingness to pay for an increased survival rate was elicited as an annual individual fee for 10 years, and the key phrase was, 'The programme will reduce your own and others' risk [of dying from cardiac arrest] and the survival rate will be increased from 5 to 10 percent on average'. Baseline survival rates are based on Swedish data and increase in the ranges we propose are feasible to achieve, since survival varies markedly among countries and even within countries (Hollenberg et al., 2005). A provision condition requiring that at least 50 percent of the inhabitants of the municipality must be in favour of the programme for it to be implemented (i.e. a referendum format) was included, according to recommendations by the National Oceanic and Atmospheric Administration (NOAA) panel (Arrow et al., 1993).

\section{Results}

First, we examined the proportions of yes-responses by bid amount (Figure 1) and found that they decline from 85 percent at the SEK 200 bid level to 16 percent at the SEK 5000 bid level ( $€ 1=$ SEK 10.53, \$1=SEK 7.07; 10 Nov. 2009). The bid levels were chosen to capture the interval of WTP responses from the pilot study, and the sample size of each bid level was 200 questionnaires. Our survival function (Figure 1) was monotonically decreasing, which is a positive validity indicator.

In order to estimate VSL from DC data, we have to make assumptions about the distribution of the underlying WTP to calculate mean and median WTP. Following Bateman et al. (2002) we start by estimating a non-parametric model to derive lower bound estimates of mean and median WTP. The conservative Kaplan-Meier-Turnbull (KMT) estimator is calculated. As lower and upper intervals we use SEK 0 and SEK 5000. Table 2 shows that the mean VSL for the conservative KMT model is SEK 49 million and the median VSL SEK 30 million. The marginal risk reduction $(\Delta \mathrm{p})$ in our CV survey was 3.35/100 000 .

\footnotetext{
${ }^{5}$ The valuation scenario and the WTP questions are included in the Appendix. Besides this text, respondents were also informed about general statistics about OHCA, e.g. incidence per year, risk levels at different ages (for men/females).
} 
Figure 1: Proportions of yes-responses by bid amount

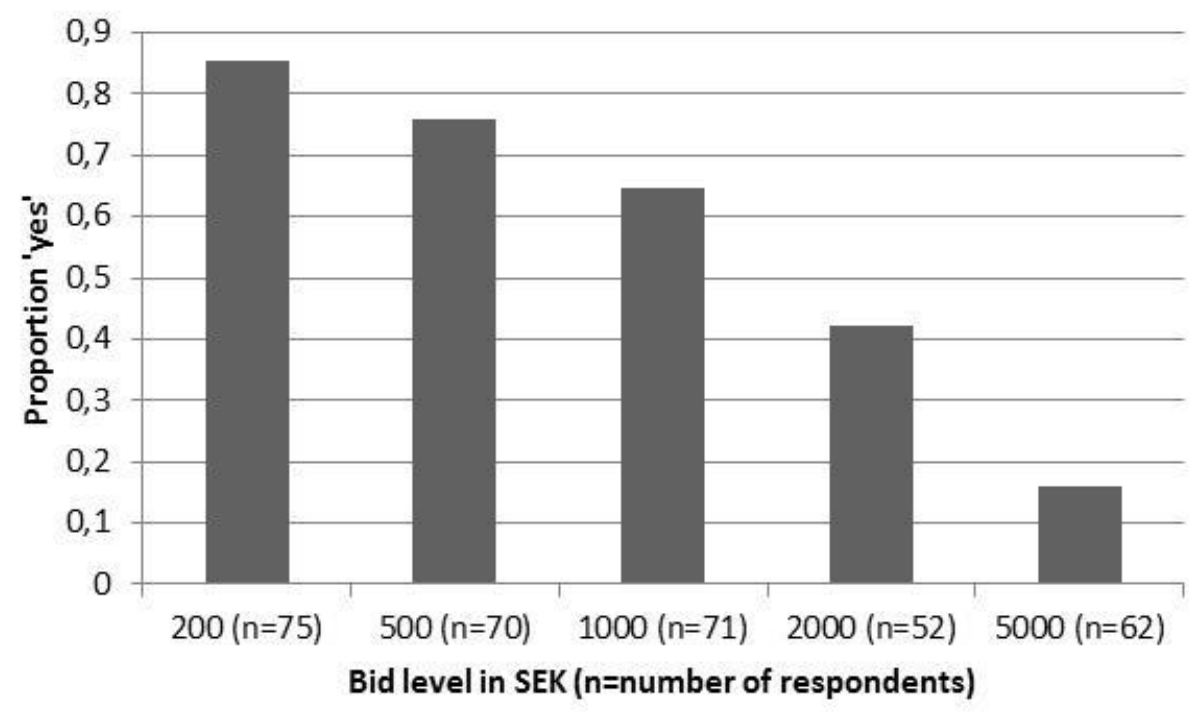

Table 2: $\quad$ Mean and median VSL (million SEK)

\begin{tabular}{lllll}
\hline & Mean VSL & 95 percent CI & Median VSL & 95 percent CI \\
\hline $\begin{array}{l}\text { Non-parametric model } \\
\text { Kaplan-Meier-Turnbull }\end{array}$ & 49 & $39-58$ & 30 & $0-149$ \\
$\begin{array}{l}\text { Parametric model } \\
\text { Logit }\end{array}$ & 63 & $51-78$ & 63 & $51-78$ \\
\hline
\end{tabular}

Further, we have estimated a variety of constant-only bid function parametric models (logit, probit, logit positive, lognormal and mixed spike/lognormal). A constant-only bid function model includes the parameter estimate for the constant alone, i.e. for logit and probit distributions the WTP function for individual $\mathrm{k}$ is $W T P_{k}=\beta_{\text {cons } \tan t}+\varepsilon_{k}$. The confidence intervals from all parametric estimations of mean and median WTP are numerically estimated by employing bootstrapping with 10000 replications. The variation of VSL values is large, but none of the values are smaller than the non-parametric KMT estimates. The 'best' parametric model, i.e. the model with the highest value for the likelihood function (Bateman et al., 2002), is the lognormal distribution. However, we notice that the differences are small and since the standard parametric approach in estimating VSL is logit, probit or probit positive, we use the most conservative result (logit).

Mean VSL is larger than median VSL for the non-parametric model. This indicates a positively skewed distribution. Median VSL can be said to be a more robust measure than mean VSL since it is not so greatly influenced by a few high VSL values or by the chosen distributional assumption. However, the choice of mean or median VSL is also a choice between an efficiency criteria and a majority voting rule as well as an ethical decision (Bateman et al., 2002; Johansson et al., 1989; Hanemann, 1989). If the mean VSL is higher than the cost per head, then the project should proceed since the losers can be compensated by the gainers (Hicks-Kaldor criteria). On the other hand, if median VSL is higher than the 
cost per head, then we know that a majority of the respondents would vote in favour of the project.

\section{Discussion}

In this paper, we have attempted the first estimation, to our knowledge, of the value of a statistical life for out-of-hospital cardiac arrest. Our results show that a conservative value, based on a non-parametric model, would be in the range of SEK 30 to 50 million. This result is interesting in two respects: (1) we do not support a 'senior death discount' for this cause of death, and (2) we can give a recommendation about a policy VSL for OHCA.

What we would like to highlight in the first respect is that we find that the estimates are consistently higher than the official VSL for road traffic safety in Sweden, which is estimated to SEK 24 million (Trafikverket, 2012). Our hypothesis was that the VSL for OHCA would be significantly lower, since statistical lives are both longer and 'healthier' for road traffic victims. We acknowledge that published WTP studies using Swedish data for road traffic accidents report equally high values or higher values, but studies with public good contexts all report lower VSL values than we find by using parametric modelling of VSL for OHCA (Hultkrantz and Svensson, 2012).

A speculation about why this unexpected difference exists could be that the cause of death is important when examining WTP for death risk reductions, as was found by Norinder et al. (2001). We might measure some kind of preference for 'individual freedom', compared to further road traffic safety measures that are perceived as limiting freedom of action (e.g. speed cameras, seat belts, helmets). An increased density of defibrillators does not affect individuals in this way. Also, we may capture solidarity with older and helpless individuals suffering from an OHCA, while road-users are perceived to have more controllable risks to manage. The qualitative characteristics of a risk have been shown to affect WTP, and WTP is usually reduced if the target group of the intervention is perceived as being blameworthy of the risk (Viscusi, 2010; Slovic, 1987).

It is fair to say that the stated preference technique in general - in this case represented by the contingent valuation method - and our small-scale survey in particular suffer from a number of potential biases and limitations. Using surveys to ask about hypothetical payments may result in e.g. hypothetical bias, where individuals' WTP from the hypothetical scenario deviate from WTP in a real market situation, or in scope/scale bias, where individuals are insensitive to the amount of a good (scope) or the size of a good (scale). Several validity types need to be considered in the context of stated preference methods (Kling et al., 2012).

In fact, the results of a scope test on our data do not support the prediction of expected utility theory, i.e. that WTP for a mortality risk reduction increases with the amount of risk reduction (weak scope sensitivity). The detailed analysis from our scope test is presented elsewhere (Sund, 2009), but the implication of the level of VSL would be a halved value (WTP is basically the same while the marginal risk reduction increased from 3.35 to 6.7 per 100.000). VSL for OHCA would still be significantly above the official VSL for road traffic accidents in Sweden, but it raises important concerns about the validity. Several VSL studies, especially in the case of valuing low-level changes in health risks, has been shown to suffer from scope insensitivity (Hammitt and Graham , 1999).

Hypothetical bias is found to be a serious problem and several meta-analyses confirm that $\mathrm{CV}$ often overstates real economic values by as much as 135 to 300 percent (List \& Gallet, 2001; Little \& Berrens, 2004; Harrison \& Rutström, 2005; Murphy et al., 2005). It is increasingly found that incorporating respondent uncertainty can potentially improve the predictive power of CV data (e.g. Blomquist et al., 2009; Blumenschein et al., 
2008). One example of an empirical treatment is to use a follow-up certainty scale of 1 (very uncertain) to 10 (very certain) and recoding all yes-responses to no-responses if the respondents were not completely certain (i.e. <10). The no-responses remain unchanged. This empirical 'certainty approach' is quite common, but in our survey the VSL for OHCA would be a negative value if we apply this treatment. ${ }^{6}$

The estimate is also sensitive to assumptions of the distribution and this is not an unusual feature of stated preference surveys (Alberini, 2005). Clearly, different methods give different results, but we have consistently applied a conservative approach. The survey method and scenario presentation we used in asking WTP questions is very similar to the technique used for eliciting traffic VSL. In the face of these uncertainties, we consider the method a possibility to achieve an indication of the value of non-market goods.

Implicit VSLs have shown considerable differences in societal investments for lifesaving interventions, which puts into question the rationality behind the implemented policies (Goebbels et al., 2008; Ramsberg and Sjöberg, 1997). Economic evaluations regarding OHCA interventions have almost exclusively relied on performing costeffectiveness analyses (CEA) or cost-utility analyses (CUA) (Forrer et al., 2002; Nichol et al., 2003; Walker et al., 2003; van Alem et al., 2004; Næss and Steen, 2004; Groeneveld and Owens, 2005). This is unfortunate since these analyses are less informative than a CBA and since a measure of VSL is essential in optimising policy in fields where weighing the saving of human lives against other effects and costs frequently occur. Presenting a CBA as a complement to CEA or CUA may improve the comparability of societal policies as well as rationality.

We do not intend to draw too far-reaching conclusions from only one small sample survey. As we have seen from the validity tests: failed scope test and no significant effect of factors which would be expected to have an effect (e.g. income level and higher perceived risk), there clearly is uncertainty as to whether our findings represent the true valuation of the respondents. Although data suggests that a lower bound of VSL for OHCA would be in the range of SEK 30 to 50 million, it might in fact be significantly higher or lower.

We recommend that a conservative approach be taken when applying our estimates for cost-benefit purposes and that it be used as a complement to CEA and/or CUA analyses. At the same time, the results indicate that there is no reason to suspect that the baseline VSL value used in the transport sector (SEK 24 million) constitutes an overestimation when used in connection with OHCA policy interventions. We therefore recommend a VSL of SEK 24 million for public programmes that affect survival rates for OHCA victims.

\section{Acknowledgements}

I would like to thank Peter Frykblom, Catharina Hjortsberg, Jacob Hollenberg, Lars Hultkrantz, Henrik Jaldell, Ulf Persson, Leif Svensson and Mikael Svensson for helpful comments and Mikael Gustafsson, Lars Hallander, Åke Karlsson, Johan Lahti, Britt Stålhandske and Sandra Wallberg for research assistance.

\footnotetext{
${ }^{6}$ How can we interpret a negative VSL value? The reason why it occurs is because the logit model allows for negative bid sums when analyzing data from dichotomous choice alternatives. If we apply the described 'certainty approach' on our data (added to a number of zero-responses), we end up with the largest share of the WTP distribution below zero, i.e. the mean WTP is negative.Negative WTP is not uncommon in CV studies (see e.g. Bohara et al., 2001) and can be handled by different models or restrictions. However, the parametric approaches we compare our estimated data with apply the logistic distribution and in this case it leads to an underestimation of WTP (and a negative VSL value).
} 


\section{Funding}

Financial support from the Swedish Civil Contingencies Agency is gratefully acknowledged.

\section{Conflict of interests}

None.

\section{References}

Alberini, A. (2005). What is a life worth? Robustness of VSL values from contingent valuation surveys. Risk Analysis, 25(4), 783-800.

van Alem, A.P., Dijkgraaf, M.G.W., Tijssen, J.G.P., and Koster, R.W. (2004). Health system costs of out-of-hospital cardiac arrest in relation to time to shock. Circulation, 110, 1967-1973.

Aldy, J.E., and Viscusi, W.K. (2007). Age differences in the value of statistical life: revealed preference evidence. Review of Environmental Economics and Policy, 1(2), 241-260.

Arrow, K., Solow, R., Portney, R., Leamer, E.E., Radner, R., and Schuman, H. (1993). Report of the NOAA panel on contingent valuation. Federal Register, January 15, 58(10), 4601-4614.

Bateman, I.J., Carson, R.T., Day B., Hanemann, M., Hanley, N., Hett, T., Jones-Lee, M., Loomes, G., Mourato, S., Özdemiroglu, E., Pearce, D.W., Sugden, R., and Swanson, J. Economic valuation with stated preference techniques. A manual. Department for Transport. Edward Elgar, 2002.

Blomquist, G.C., Blumenschein, K. and Johannesson, M., (2009). Eliciting willingness to pay without bias using follow-up certainty statements: Comparisons between probably/definitively and a 10-point certainty scale. Environmental and Resource Economics; 43, 473-502.

Blumenschein, K., Blomquist, G.C., Johannesson, M., Horn, N. and Freeman, P., (2008). Eliciting willingness to pay without bias: Evidence from a field experiment. Economic Journal, 118, 114-137.

Bohara, A.K., Kerkvliet, J. and Berrens, R.P. (2001). Addressing negative willingness to pay in dichotomous choice contingent valuation. A Monte Carlo simulation. Environmental and Resource Economics, 20, 173-195.

Carson, R.T., and Groves, T. (2007): Incentive and informational properties of preference questions. Environmental and Resource Economics, 37, 181-210.

Corso, P.S., Hammitt, J.K. and Graham, J.D., (2001). Valuing mortality risk-reduction: Using visual aids to improve the validity of contingent valuation. Journal of Risk and Uncertainty, 23(2), 165-184.

Evans, M.F., and Smith, V.K. (2006). Do we really understand the age-VSL relationship? Resource and Energy Economics, 28, 242-261.

Forrer, C.S., Swor, R.A., Jackson, R.E., Pascual, R.G., Compton, S., and McEachin, C. (2002). Estimated cost effectiveness of a police automated external defibrillator program in a suburban community: 7 years experience. Resuscitation, 52, 23-29.

Goebbels, A.F.G., Novák, A., Veraart, C.P.W.M., and Severens, J.L. (2008). Estimating the implicit value of statistical life based on public interventions implemented in The Netherlands. International Journal of Technology Assessment in Health Care, 24(4), 495-501.

Groeneveld, P.W., and Owens, D.K. (2005). Cost-effectiveness of training unselected laypersons in cardiopulmonary resuscitation and defibrillation. The American Journal of Medicine, 118, 5867. 
Hammitt, J.K. and Graham, J.D., (1999). Willingness to pay for health protection: Inadequate sensitivity to probability? Journal of Risk and Uncertainty, 18, 33-62.

Hanemann, W.M. (1989). Welfare evaluations in contingent valuation experiments with discrete response data: Reply. American Journal of Agricultural Economics, November 1989, 71(4), 1057-1061.

Hanemann, W.M., (1984). Welfare evaluations in contingent valuation experiments with discrete responders. American Journal of Agricultural Economics, 66, 332-341.

Harrison G.W. and Rutstrom E.E. (2005). Experimental evidence on the existence of hypothetical bias in value elicitation methods. In: C. Plott and V. Smith (eds.), Handbook in Experimental Economic Results. Elsevier Science, New York.

HEATCO. (2006). Proposal for harmonised guidelines. HEATCO Deliverable 5, Second revision, February 2006, IER, Germany. (Accessed 7 November 2008, at http://heatco.ier.unistuttgart.de/ ).

Hoehn, J. and Randall, A. (1987). Satisfactory Benefit-Cost Indicator. Journal of Environmental Economics and Management, 14(September), 226-47.

Hollenberg, J., Bång, A., Lindqvist, J., Herlitz, J., Nordlander, R., Svensson, L. and Rosenqvist, M., (2005). Difference in survival after out-of-hospital cardiac arrest between the two largest cities in Sweden: a matter of time? Journal of Internal Medicine, 257, 247-254.

Hultkrantz, L. and Svensson, M. (2012). The value of a statistical life in Sweden: A review of the empirical literature. Health policy, 108, 302-310.

Hultkrantz, L., Lindberg, G., and Andersson, C. (2006). The value of improved road safety. Journal of Risk and Uncertainty, 32, 151-170.

Johansson, P-O., Kriström, B., and Mäler, K.G. (1989). Welfare evaluations in contingent valuation experiments with discrete response data: Comment. American Journal of Agricultural Economics, November 1989, 71 (4), 1054-1056.

Jones-Lee, M. (1974). The value of changes in the probability of death and injury. Journal of Political Economy, 82(4), 835-849.

Kling, C.L., Phaneuf, D.J. and Zhao, J. (2012). From Exxon to BP: Has some number become better than no number? Journal of Economic Perspectives, 26(4), Fall 2012, 3-26.

Klose, T. (1999). The contingent valuation method in health care. Health Policy, 47, 97-123.

Krupnick, A. (2007). Mortality-risk valuation and age: stated preference evidence. Review of Environmental Economics and Policy, 1(2), 261-282.

List J.A. and Gallet C.A., (2001). What experimental protocol influence disparities between actual and hypothetical values? Evidence from meta-analysis. Environmental and Resource Economics, 20, 241-254.

Little J. and Berrens R, (2004). Explaining disparities between actual and hypothetical stated values: further investigation using meta-analysis. Economics Bulletin , 3, (6), 1-13.

Murphy J.J. Allen, P. Geoffrey S, Thomas H. and Weatherhead D, (2005). A meta-analysis of hypothetical bias in stated preference valuation. Environmental and Resource Economics, 30, 313-325.

Næss, A., and Steen, P.A. (2004). Long term survival and costs per life year gained after out-ofhospital cardiac arrest. Resuscitation, 60, 57-64.

Nichol, G., Valenzuela, T., Roe, D., Clark, L., Huszti, E., and Wells, G.A. (2003). Cost effectiveness of defibrillation by targeted responders in public settings. Circulation, 108, 697-703.

Norinder, A,, Hjalte, K., and Persson, U. (2001). Scope and scale insensitivities in a contingent valuation study of risk reductions. Health Policy, 57, 141-153.

Persson, U., Norinder, A., Hjalte, K., and Gralén, K. (2001). The value of a statistical life in transport: Findings from a new contingent valuation study in Sweden. Journal of Risk and Uncertainty, 23, 121-134. 
Ramsberg, J.A.L., and Sjöberg, L. (1997). The cost-effectiveness of lifesaving interventions in Sweden. Risk Analysis, 17(4), 467-478.

Slovic, P. (1987). The perception of risk. Science, 17 April 1987, 236(4799), 280-285.

Sund, B. (2009). Sensitivity to scope in contingent valuation - introducing a flexible community analogy to communicate mortality risk reductions. Örebro University. School of Business. Working Papers, 2009:2.

Sund, B., Svensson, L., Rosenqvist, M., and Hollenberg, J. (2012). Favourable cost-benefit in an early defibrillation programme using dual dispatch of ambulance and fire services in out-ofhospital cardiac arrest. European Journal of Health Economics, 13, 811-818.

Svensson, M. (2009). Precautionary behavior and willingness to pay for a mortality risk reduction: Searching for the expected relationship. Journal of Risk and Uncertainty, 39, 65-85.

Trafikverket (The Swedish Transport Administration). (2012). Samhällsekonomiska principer och kalkylvärden för transportsektorn: ASEK 5. Kapitel 9 Trafiksäkerhet. Version 2012-05-16. (In Swedish). (Accessed 19 February 2014, at http://www.trafikverket.se/PageFiles/73641/ samhallsekonomiska_principer_och_kalkylvarden_for_transportsektorn_asek_5_kapitel_9_tr afiksakerhet_2.pdf).

Viscusi, W.K. (2010). The heterogeneity of the value of statistical life: Introduction and overview. Journal of Risk and Uncertainty, 40, 1-13.

Walker, A., Sirel, J.M., Marsden, A.K., Cobbe, S.M., and Pell, J.P. (2003). Cost effectiveness and cost utility model of public place defibrillators in improving survival after prehospital cardiopulmonary arrest. BMJ, 6 December 2003, 327, 1316.

(C) 2017 by the author(s). This article is an open access article distributed under the terms and conditions of the Creative Commons Attribution license (http://creativecommons.org/licenses/by/4.0/). 
Appendix

Table A1: The valuation scenario and WTP questions for the contingent valuation survey

A number of individuals suffer from cardiac arrests each year in your municipality. Imagine that there exists a possibility to reduce mortality risks for cardiac arrests. We will ask you about your willingness to pay for such measures. Remember that the money you are willing to pay for security improvements reduces your possibilities for other consumption.

To reduce the mortality risk a public programme to increase the density of defibrillators is considered. One possibility is to equip and educate employees within certain professions in the municipality which may respond faster than the ambulance. These professions might be firemen, policemen, security guards or nurses. Public access defibrillators may also be located in hotels, shopping malls, sports centres or theatres.

A prerequisite for the programme to be implemented is that at least $50 \%$ of the individuals in your municipality are positive to the introduction of the programme. The cost is paid as an annual fee. If the individuals will not contribute enough with the fee, the programme will not be imposed.

\section{What is the effect of the programme?}

The programme will result in your own risk as well as the risk of all other individuals in your municipality being reduced, and the survival rate will increase from $5 \%$ to $10 \%$ on average. In the table the effect of the programme for various municipality sizes are presented.

Observe that the table represents effects over 10 years!

\begin{tabular}{llll|l}
\hline Inhabitants & $\begin{array}{l}\text { Number of out-of- } \\
\text { hospital cardiac } \\
\text { arrests over 10 years }\end{array}$ & $\begin{array}{l}\text { Number of } \\
\text { survivors over 10 } \\
\text { years (before), 5\% }\end{array}$ & $\begin{array}{l}\text { Number of } \\
\text { survivors over 10 }\end{array}$ & \multicolumn{2}{c}{ Difference } \\
\hline 10000 & 70 & 3 & 7 & 13 \\
20000 & 130 & 6 & 20 & +4 \\
30000 & 200 & 10 & 33 & +7 \\
50000 & 330 & 16 & 50 & +10 \\
75000 & 500 & 25 & 67 & +25 \\
100000 & 670 & 33 & 100 & +34 \\
150000 & 1000 & 50 & 167 & +50 \\
250000 & 1670 & 83 & 335 & +84 \\
500000 & 3350 & 167 & 502 & +168 \\
750000 & 5020 & 251 & & +251 \\
\hline
\end{tabular}

Example from the table: In a municipality of 10000 individuals, 70 persons will suffer from out-of-hospital cardiac arrest during a 10 year period on average. Now 3 persons will survive and after the programme 7 persons will survive, which implies an increase of 4 persons over 10 years. 
Question 10. How would you vote if your personal fee was SEK 200 per year (i.e total SEK 2000 for 10 years), for this programme to be implemented in your municipality?

I would vote: $\square$ Yes $\square$ No

Question 12. Provided that the programme is carried out, how much would you at most be willing to pay annually for the implementation of the programme, that reduces your own risk as well as the risk of all other individuals in your municipality for a cardiac arrest mortality?

Answer: ..SEK per year

Note: The survey was divided into two sub-samples that use two different aids to communicate the risk reduction. We present the valuation scenario of the 'flexible community analogy', but also used an array of dots (see e.g. Corso et al., 2001). There was no difference in WTP between the samples.

\section{Table A2: $\quad$ Sample statistics}

\begin{tabular}{|c|c|c|c|c|}
\hline Variable & Definition & $\begin{array}{l}\text { Mean } \\
\text { (std.dev.) }\end{array}$ & Min & Max \\
\hline Female & Gender $=$ female & $\begin{array}{l}0.50 \\
(0.50)\end{array}$ & 0 & 1 \\
\hline Age & Age of the respondent & $\begin{array}{l}48.3 \\
(15.3)\end{array}$ & 17 & 75 \\
\hline $\begin{array}{l}\text { High } \\
\text { education }\end{array}$ & Education level is at least one term at a university & $\begin{array}{l}0.44 \\
(0.50)\end{array}$ & 0 & 1 \\
\hline $\begin{array}{l}\text { Low } \\
\text { education }\end{array}$ & $\begin{array}{l}\text { Education level is at most nine-year compulsory } \\
\text { school }\end{array}$ & $\begin{array}{l}0.18 \\
(0.39)\end{array}$ & 0 & 1 \\
\hline High risk & $\begin{array}{l}\text { Own perceived risk of cardiac arrest is higher than } \\
\text { average }\end{array}$ & $\begin{array}{l}0.16 \\
(0.36)\end{array}$ & 0 & 1 \\
\hline Low risk & $\begin{array}{l}\text { Own perceived risk of cardiac arrest is lower than } \\
\text { average }\end{array}$ & $\begin{array}{l}0.41 \\
(0.49)\end{array}$ & 0 & 1 \\
\hline Income & $\begin{array}{l}\text { The income }(\mathrm{SEK}) \text { per consumption unit given by the } \\
\text { total household income* divided by the number of } \\
\text { household members weighted as follows: adult person } \\
\# 1=1.16 \text {, adult person } \# 2=0.76 \text {, children } 0-3 \text { years } \\
\text { old }=0.56 \text {, children } 4-10 \text { years old }=0.66 \text {, children } 11 \text { - } \\
17 \text { years old }=0.76\end{array}$ & $\begin{array}{l}19223 \\
(10992)\end{array}$ & 1220 & 68966 \\
\hline Population & $\begin{array}{l}\text { Number of inhabitants (self-assessed by respondents) } \\
\text { of the municipality }\end{array}$ & $\begin{array}{l}147676 \\
(227607)\end{array}$ & 3000 & 1000000 \\
\hline Heart & The respondent has suffered from heart disease & $\begin{array}{l}0.11 \\
(0.31)\end{array}$ & 0 & 1 \\
\hline
\end{tabular}

* The respondents were asked to mark an interval with a range of SEK 4999.The income was then approximated by using the mid value of the interval. 